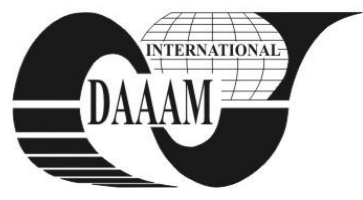

Annals of DAAAM for 2011 \& Proceedings of the 22nd International DAAAM Symposium, Volume 22, No. 1, ISSN 1726-9679 ISBN 978-3-901509-83-4, Editor B. Katalinic, Published by DAAAM International, Vienna, Austria, EU, 2011 Make Harmony between Technology and Nature, and Your Mind will Fly Free as a Bird Annals \& Proceedings of DAAAM International 2011

\title{
SIMULATION OF DEFORMATION AND COMPRESSION OF FABRIC DURING THE BACK INJECTION MOULDING PROCESS
}

\author{
AUSPERGER, A[les]
}

\begin{abstract}
This paper deals with the possibility of a simulation model development for fabric deformation prediction during closing injection mould, and prediction of fabric compression by molten plastic during filling and pressing when using the back-injection moulding technology. Deformations are simulated by using T-SIM programme, and verified on the experimental shaping device, where the deformation measurement is done by using the Aramis system. A measure apparatus was designed to measure surface fabric compression resulting from molten plastic pressure and temperature; it allows temperature, pressure, and time variations. Fabric compression dependence on these parameters is input information for injection process simulation.

Key words: T-SIM, simulation model, shaping of fabrics, fabric compression, back injection moulding
\end{abstract}

\section{INTRODUCTION}

Back-injection moulding (BIM) is used in many industries, especially in large-lot production. It enables cheap manufacturing of upholstery and interior parts mainly in automotive industry, or for example in furniture-making industry too. Fabric trim is inserted directly into the injection mould, due to mould closing the trim is remoulded; and subsequently covered by molten plastic. Fabric and plastic are inseparably connected during this process. This process is already quite widespread in practice, but nobody has really dealt with question about such process simulation. Based upon the experience of the constructor, the trim shape is designed; verification of this design is actually possible when manufacturing already starts. It might induce additional costs for adjusting of moulds, fabric trims etc. Therefore an effort has been made to solve the shape of the trim, fabric fixing in the mould, and potential defects by simulation calculation in the pre-production period.

\section{THEORETICAL BASE}

In academic environment and industry practice are the computer systems common part of tools and technology process design (Taraba \& Hajdu, 2010). It is necessary to divide the calculation procedure of BIM process into individual stages. 1. Stage - fabric moulding during closing injection mould. 2. Stage - fabric moulding caused by flowing molten plastic. 3. Stage - fabric compression caused by the temperature and pressure. It is possible to predicate metal forming (Vilcans \& Torims, 2010) and plastic moulding with high probability. Fabric moulding is more complicated because of large qualities changes in the loading direction. Tensile tests are carried out in the direction from $0^{\circ}$ to $180^{\circ}$ with minimal increment $15^{\circ}$ to create a material model describing behaviour of fabrics. The model prepared upon this data well describes 2D behaviour of fabric during the moulding simulation analysis; for the BIM technology, it enables to predicate areas of deformation causing appearance defects, and to predicate fabric deformation during an injection mould closing. However, this process does not allow to exactly determining the changes in fabric thickness. During injection, fabric is exposed to high pressure and temperature introduced by the injected molten plastic. It might lead to melting down and size reduction of fabric foam parts (Hajdu \& Taraba, 2010). At the spots with slightly molten foam layer, the resulting product reveals decreasing of utility properties because of harder surface. To determine fabric compression in pre-production stage, it is suitable to use plastic injection simulation programme (Cadmould, Autodesk Modflow, Moldex 3D...) (Kyas et al., 2010), which provides results for time and values of temperature and pressure that loaded fabric during injection. It is possible to compare values obtained by the simulation analysis with tests of fabric exposed to temperature and pressure for different periods of time.

\section{SIMULATION MODEL}

To verify fabric material model, an experimental shaping device was created; it enables to change the punch entering shaped fabric and the shape of fixing of fabric (fig. 1). The simulation model was built in the T-SIM programme and it corresponds to the dimensions used for experimental device. The number of calculation elements is 30000 . In the model, fixing of fabric is solved by setting the boundary conditions.

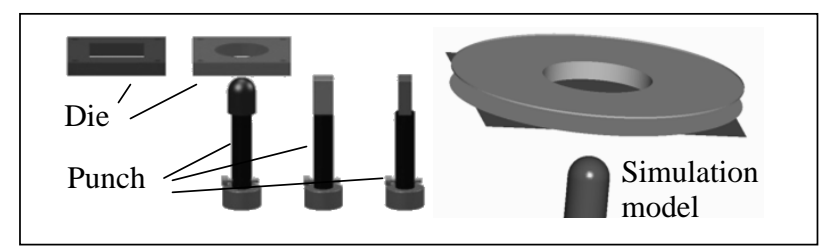

Fig. 1. Shaping device and simulation model

Results already from the punch entering the shaped fabric up to its maximum $(25 \mathrm{~mm})$ were continuously monitored; and after the punch returned back to the starting position, the result was recorded too (fig. 2).

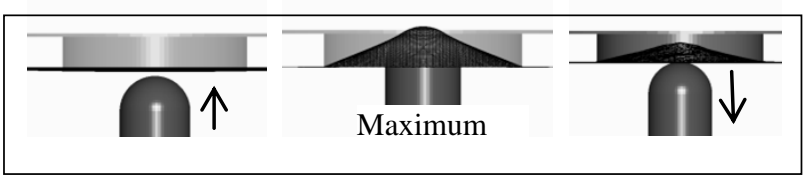

Fig. 2. Deformation process during simulation of shaping.

\section{EXPERIMENTAL PART}

Deformations of fabric during the experimental measurement were monitored by contactless digitalization of the shape in the Aramis system (Sobotka, 2010). Before the measurement itself, it was necessary to prepare the fabrics surface by the stochastic pattern. It is easy to digitalize such pattern created this way. During the experiment, saved shape results corresponded to the shift of the punch by $5 \mathrm{~mm}$. 
The second part of the experiment was focused on values of fabric compression by high pressure and temperature. To determinate these values, a measuring device was made (fig. 3), it enables to set conditions similar to those in the injection mould during BIM technology. During the manufacturing process, the visible side of fabric is in contact with injection mould $\left(20-80^{\circ} \mathrm{C}\right)$, and the contact side is compressed by hot molten plastic $\left(120-180^{\circ} \mathrm{C}\right)$. The device is adaptable, so it can be fixed on the injection moulding machine and used for other commonly available peripheries. The plate representing injection mould is connected to a tempering unit and thus tempered. The heated part is connected to the machine via interface that controls heating and regulation of hot runners. The source of force, i.e. pressure, is the clamping mechanism of the injection moulding machine. Under following temperatures $20,150,160,170,180,190$ and $200^{\circ} \mathrm{C}$, pressures 30,40 a 50 $\mathrm{MPa}$, time of exposure 20,30,40,50 and $60 \mathrm{~s}$, mould temperatures $20,50,80^{\circ} \mathrm{C}$ was experiment measured.

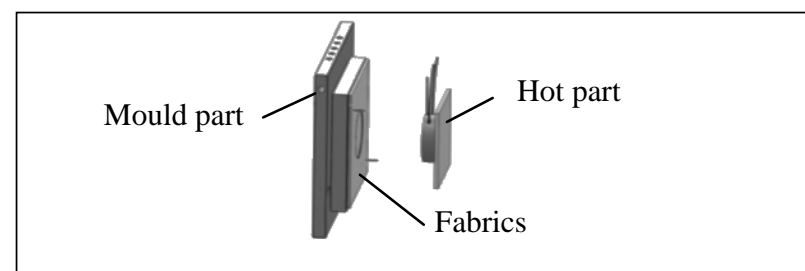

Fig. 3. Device for compression of fabric by temperature and pressure

\section{OBTAINED RESULTS}

Experimental measurements and simulation analysis provided results for identical situations of fabric deformation process. Results measured by the Aramis system, which is designed for contactless surface dynamic digitalization of components, serves as a description of a real situation. Figure 4 shows both results from the Aramis system and from the simulation in T-SIM programme for the same positions of the punch as in figure 2. Also, in figure 4 there is an image of fabric deformation in the shaping device. The accuracy of the simulation is evaluated by the deviation from a real shape.

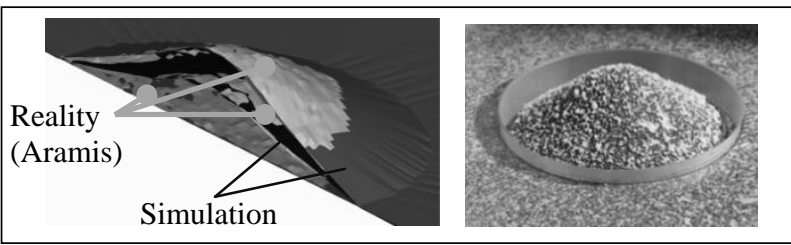

Fig. 4. Comparison of results obtained from the simulation and from the Aramis system, an image of shaped fabric

Based on fabric compression results, it is possible to find limits for quality of components. From the quality requirements point of view, when tested fabric is used, its compression from original thickness $3.8 \mathrm{~mm}$ under the value $3 \mathrm{~mm}$ is unacceptable. The diagram in figure 5 illustrates compression when pressure of $40 \mathrm{MPa}$ is applied.

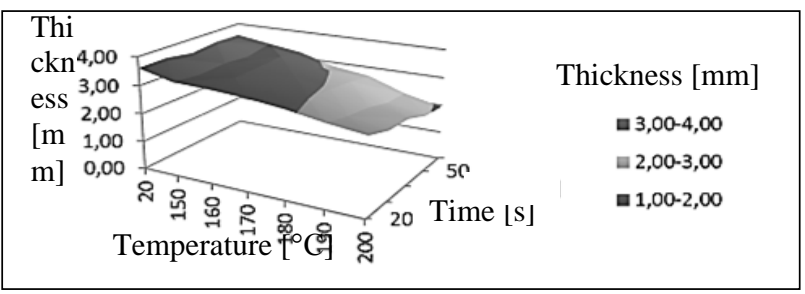

Fig. 5. Fabric compression in dependence on temperature and time variations for the pressure of $40 \mathrm{MPa}$

\section{DISCUSSION}

In all combinations of punches and fixing shapes, the developed mathematical model for deformation of tested fabric reveals an accordance exceeding value of $90 \%$ in comparison with experimental measurement. Development of such model for one kind of fabric is very demanding and requires a large number of experiments supported by quality feedback.

Through experimental measurement of fabric compression, it was found out that mould temperature did not have statistically significant influence on compression of tested fabric. The results helped to find limit temperature-pressure conditions which must be avoided at production in order to prevent manufacturing of defective components.

\section{CONCLUSION}

When the tested fabric is used in the back injection moulding process, it is possible to use the developed model in the T-SIM programme to simulate a deformation process that occurs during injection mould closing. It is necessary to use injection simulation results (temperature, pressure, time) to determine the extent of fabric compression during injection. Following research will aim at automatic evaluation of compression directly in simulation programme. Device for fabric compression by pressure and temperature can be used in practice when choosing fabric suitable for back injection moulding technology.

\section{ACKNOWLEDGEMENTS}

This paper was realised with the support of Czech Science foundation GACR 101/09/P639.

\section{REFERENCES}

Hajdu, S. \& Taraba, B. (2010). The Numerical Approach to the Calculation of Combined Heat Transfer Coefficient for Cooling Probe Immersed in Agitated Quenching Oil, Annals of DAAAM for 2010 \& Proceedings of the 21st International DAAAM Symposium, 20-23rd October 2010, Zadar, Croatia, ISSN 1726-9679, ISBN 978-3-901509-735, Katalinic, B. (Ed.), pp. 1141-1142, Published by DAAAM International Vienna, Vienna

Kyas, K.; Stanek, M.; Manas, M.; Manas, D.; Krumal, M. \& Cerny, J. (2010). Polymer Injection Molding Process Simulation, Annals of DAAAM for 2010 \& Proceedings of the 21st International DAAAM Symposium, 20-23rd October 2010, Zadar, Croatia, ISSN 1726-9679, ISBN 9783-901509-73-5, Katalinic, B. (Ed.), pp. 1081-1082, Published by DAAAM International Vienna, Vienna

Sobotka, J. (2010). Formability of TWIP Materials and its Evaluation by Optical System, Tribun EU s.r.o., ISBN 97880-7372-681-2, Liberec

Taraba, B. \& Hajdu, S. (2010). Experiences with Education of CAE Software in Academic Environment Supported by Model Task, Annals of DAAAM for 2010 \& Proceedings of the 21st International DAAAM Symposium, 20-23rd October 2010, Zadar, Croatia, ISSN 1726-9679, ISBN 9783-901509-73-5, Katalinic, B. (Ed.), pp. 0543-0544, Published by DAAAM International Vienna, Vienna

Vilcans, J. \& Torims, T. (2010). Thin Sheet Metal Stamping with Elastic Media, Annals of DAAAM for 2010 \& Proceedings of the 21st International DAAAM Symposium, 20-23rd October 2010, Zadar, Croatia, ISSN 1726-9679, ISBN 978-3-901509-73-5, Katalinic, B. (Ed.), pp. 08490850, Published by DAAAM International Vienna, Vienna 